\title{
Chemical Composition and Antioxidant Activity of Solenostemma oleifolium Essential Oil From Southern Algeria
}

\author{
Ilyas Chikhi ${ }^{1,2 *}$, Fayçal Dergal ${ }^{3}$, Djazia Meryem Gana ${ }^{2}$, Mohammed El Amine Dib ${ }^{1}$, Hanane Chaker ${ }^{2,4}$ \\ ${ }^{1}$ Laboratoire des Substances Naturelles et Bioactives (LASNABIO), Université de Tlemcen, BP 119, 13000, Algérie \\ ${ }^{2}$ Centre Universitaire Belhadj Bouchaib - Ain Témouchent, Algérie \\ ${ }^{3}$ Centre de Recherche Scientifique et Technique en Analyses Physico-chimique, C.R.A.P.C, Bp 384, Bousmail, Algérie \\ ${ }^{4}$ Laboratoire de Catalyse et Synthèse en Chimie Organique BP 119, Université de Tlemcen, Algérie
}

Corresponding Author: Ilyas Chikhi, Laboratoire des Substances Naturelles et Bioactives (LASNABIO), Université de Tlemcen, BP 119, 13000, Algérie. Email: c.ilyas@hotmail.fr

Received March 23, 2019; Accepted May 22, 2019; Online Published June 17, 2019

\begin{abstract}
Introduction: Solenostemma oleifolium is a species that grows in extremely dry conditions. It is widespread at the foot of cliffs and in rocky areas. It is a medicinal plant used for the treatment of diabetes, respiratory disorders, rheumatism, stomach pain, urinary tract infections and febrifuge. As a part of this research program on natural compounds with antioxidant properties, the main objective of this study was to determine the chemical composition and the antioxidant activity of essential oil of $S$. oleifolium.

Material and Methods: In this study, the aerial parts of the plant were hydrodistilled in a Clevenger-type apparatus. The isolated essential oil was analyzed using gas chromatography mass spectrometry (GC-MS). The antioxidant activity of the essential oil was assessed using 2,2-diphenyl-1picrylhydrazyl (DPPH) and ferric-reducing power (FRAP).

Results: The essential oil of S. oleifolium was principally characterized by oxygenated monoterpenes (94.3\%) represented by linalool (59.0\%), $\alpha$-terpineol (14.5\%) and geraniol (12.4\%), followed by small amounts of nerol $(3.7 \%)$ and piperitone $(3.6 \%)$. The results of the antioxidant activity of essential oil showed an interesting propriety in the quenching of DPPH radical, with an IC50 of $3.3 \mathrm{~g} / \mathrm{L}$. On the other hand, essential oil showed the presence of the reductive effect, which increased with an increase in concentration.

Conclusions: The results of this research showed that the S. oleifolium essential oil presented an interesting antioxidant property. Actually, it could be proposed as a new potential source of natural additives for the food or pharmaceutical industries.

Keywords: Essential Oil, Antioxidant Activity, Solenostemma Oleifolium, DPPH, FRAP

Citation: Chikhi I, Dergal F, Gana DM, El Amine Dib M, Chaker H. Chemical composition and antioxidant activity of Solenostemma oleifolium essential oil from Southern Algeria. J Appl Biotechnol Rep. 2019;6(2):50-54. doi:10.29252/JABR.06.02.02.
\end{abstract}

\section{Introduction}

Antioxidants are in the form of food supplements or in the diet, they are essential to prevent many diseases. They are substances that act against oxidation, a process that leads to the formation of free radicals in the body. These free radicals are harmful and can, for example, contribute to the development of different types of cancers. Butylated hydroxyanisole (BHA) and butylated hydroxytoluene (BHT) are 2 food additives that protect fatty foods from oxidation. ${ }^{1}$ They are also found in cosmetics for the same reason. Studies have shown that both these synthetic antioxidants affect the nervous system and increase the risk of allergies and certain cancers. ${ }^{2}$ Many studies are increasingly interested in the therapeutic effects of naturally occurring antioxidants which are supposed to protect living organisms from oxidative damages. ${ }^{3}$

The use of essential oils is expanding in several sectors and in many industrial fields. Several essential oils have been attributed to good antioxidant properties, which can be exploited to protect other materials, such as food, from rancidity or to prevent the oxidative stress that contributes to the appearance of degenerative diseases. ${ }^{4}$ Essential oils and their components are known to possess antioxidant activities. ${ }^{4}$ The essential oil of basil, cinnamon, clove, nutmeg, oregano, and thyme possesses antioxidant properties due to their major terpenes such as thymol and carvacrol. ${ }^{5}$ In addition, the essential oil of Melissa officinalis, whose main components were terpenoids such as neral, geranial, citronellal, isomenthone, and menthone showed free radical scavenging activity. ${ }^{6}$ Solenostemma oleifolium belongs to the family of Asclepiadaceae and grows in the desert areas of Mali, Libya and Egypt. It is also widely distributed in Algerian Sahara. This species grows in dry condition areas and is widespread at the foot of the cliffs and in rocky areas. It is frequently used in traditional medicine against rheumatism, stomach pain,

Copyright (C) 2019 The Author(s). This is an open-access article distributed under the terms of the Creative Commons Attribution License (http:// creativecommons.org/licenses/by/4.0), which permits unrestricted use, distribution, and reproduction in any medium, provided the original work is properly cited. 
urinary tract infections, diabetes and respiratory disorders. $S$. oleifolium is a shrub that can grow up to $60 \mathrm{~cm}$ tall. The leaves are opposite, decussate, simple and entire. The petiole is 1 to $2 \mathrm{~mm}$ long; blade lanceolate. The flowers are bisexual, regular, 5-merous, white, fragrant; pedicel 2-5 mm long; calyx lobes oblong, corolla $3 \mathrm{~mm}$ long, apex acute. This plant is known as vernacular names: Ardjel. ${ }^{7,8}$ As part of the program of this research on natural compounds with antioxidant property, the main objective of this study was to determine the chemical composition and the antioxidant activity of the essential oil of S. oleifolium growing in south Algeria.

\section{Materials and Methods}

Plant Material and Extraction of the Oils

Aerial parts of S. oleifolium were collected from Tamanrasset area (Algeria) $25^{\circ} 48^{\prime} 32.87^{\prime \prime} \mathrm{N} 8^{\circ} 08^{\prime} 25.53^{\prime \prime} \mathrm{E}$, at $1276 \mathrm{~m}$ altitude during the month of April 2018. The collected plants were identified by Pr. Noury Benabadji, Laboratory of Ecology and Ecosystem Management, University of Tlemcen, (Algeria). Voucher specimens were deposited in the herbarium of the University of Tlemcen (CI.SO1.04.18). Essential oil was obtained from dry aerial parts ( $400 \mathrm{~g}$ ) by hydrodistillation (in $4000 \mathrm{~mL}$ distilled water) for 4 hours using a Clevenger-type apparatus. The obtained essential oil was pale yellow in color with a yield $(\mathrm{w} / \mathrm{w})$ of $0.5 \%$.

\section{Gas Chromatography}

Gas Chromatography (GC) analyses were carried out using an HP Agilent 6890 gas chromatograph (FID) equipped with an HP-5MS (HP Agilent) fused silica capillary column, $30 \mathrm{~m}$ $\times 0.25 \mathrm{~mm}, 0.25 \mu \mathrm{m}$ film thickness, which was perfused with helium at a flow-rate of $1 \mathrm{~mL} / \mathrm{min}$ and operated with a split ratio of 10 , essential oil injection volume was $0.2 \mu \mathrm{L}$ without dilution whereas the injection temperature was set at $250^{\circ} \mathrm{C}$. The column temperature was programmed isothermally at $80^{\circ} \mathrm{C}$ for 2 minutes, after which the temperature was increased to $240^{\circ} \mathrm{C}$ at a rate of $15^{\circ} \mathrm{C} / \mathrm{min}$.

Retention indices (RI) of the compounds were determined relative to the retention times of the series of $n$-alkanes $\left(\mathrm{C}_{5}-\mathrm{C}_{30}\right)$ with linear interpolation, using the Van den Dool and Kratz equation ${ }^{8}$ and software from HP Agilent 6890. Component relative concentrations were calculated based on GC peak areas without using correction factors.

\section{Gas Chromatography-Mass Spectrometry}

Gas Chromatography-Mass Spectrometry (GC-MS) spectra were obtained using the following conditions: carrier gas helium; flow rate $0.3 \mathrm{~mL} / \mathrm{min}$; split-less mode. Same as GC/ FID, essential oil injection volume was $0.2 \mu \mathrm{L}$ without dilution whereas the injection temperature was set at $250^{\circ} \mathrm{C}$. The oven temperature program was set at $60^{\circ} \mathrm{C}$ for 8 minutes increased at $2^{\circ} \mathrm{C} / \mathrm{min}$ to $250^{\circ} \mathrm{C}$ and held at $250^{\circ} \mathrm{C}$ for 15 minutes; and the electron impact mass spectral analysis was carried out at ionization energy of $70 \mathrm{eV}$. Constituents were tentatively identified by comparison of their GC RI, determined with reference to a homologous series of $\mathrm{C}_{5}-\mathrm{C}_{30}$ n-alkanes and with those of authentic standards available in the authors' laboratory. Identification was confirmed by comparison of their mass spectral fragmentation patterns with those stored in the MS database (National Institute of Standards and Technology and Wiley libraries).

\section{DPPH Free Radical Scavenging Assay}

The free radical-scavenging activity of essential oil was measured using DPPH as described earlier. ${ }^{10}$ Different concentrations of essential oil (0.01-30 g/L) were mixed with $1 \mathrm{~mL}$ of $90 \mu \mathrm{M}$ DPPH solution and filled up with $95 \% \mathrm{MeOH}$ to a final volume of $4 \mathrm{~mL}$. The absorbance of the resulting solutions and the blank were recorded after 1 hour at room temperature, against ascorbic acid as a positive control. For each sample, three replicates were recorded. The absorbance was read against a blank at $515 \mathrm{~nm}$. The RSC in percent was calculated by the following equation:

$\mathrm{I} \%=\left[\frac{\mathrm{A}_{\text {blank }}-\mathrm{A}_{\text {sample }}}{\mathrm{A}_{\text {blank }}}\right] \times 100 \%$

Accordingly, $\mathrm{A}_{\text {blank }}$ is the absorbance of the control reaction (without oils), and $\mathrm{A}_{\text {sample }}$ is the absorbance in the presence of essential oils. From the obtained RSC values, the $\mathrm{IC}_{50}$ values, which represented the concentrations of the essential oil caused 50\% neutralization, were determined by linear regression analysis. The essential oil samples were analyzed in three replications.

\section{Reducing Power}

The reducing power of aerial parts essential oil was determined as described earlier. ${ }^{11}$ Accordingly, $1 \mathrm{~mL}$ of different concentrations of essential oil $(0.5,0.75,1.0,1.5$ and $2.0 \mathrm{~g} / \mathrm{L}$ ) in methanol were mixed with phosphate buffer (2.5 mL, 0.2 M, pH 6.6) and potassium ferrocyanide $(2.5 \mathrm{~mL}$, $1 \%)$. The mixture was incubated at $50^{\circ} \mathrm{C}$ for 20 minutes. A portion $(2.5 \mathrm{~mL})$ of trichloroacetic acid $(10 \%)$ was added to the mixture, which was then centrifuged at $3000 \mathrm{rpm}$ for 10 minutes. The supernatant $(2.5 \mathrm{~mL})$ was then mixed with 2.5 $\mathrm{mL}$ distilled water and $0.5 \mathrm{ml}$ of $0.1 \%$ ferric chloride solution. The intensity of the blue-green colour was measured at 700 $\mathrm{nm}$. The $\mathrm{EC}_{50}$ value $(\mathrm{g} / \mathrm{L})$ is the extract concentration at which the absorbance was 0.5 for the reducing power and was calculated from the graph of absorbance at $700 \mathrm{~nm}$ against extract concentration. Ascorbic acid was used as a positive control. Tests were carried out in triplicate.

\section{Statistical Analysis}

All data are presented as the mean \pm standard deviation of three replicates. Correlation analyses of radical scavenging activities and FRAP were carried out using Microsoft Office Excel 2016.

\section{Results}

Chemical Composition of Essential Oil

The total number of chemical components identified in essential oil was twenty-three, accounting for $97.8 \%$ of the total oil composition. Among them, 17 monoterpenes, 5 sesquiterpenes and 1 non-terpenic compound were identified (Table 1). The chemical composition of $S$. 
oleifolium essential oil was represented practically only by oxygenated monoterpenes $(95.3 \%)$. The other compounds such as monoterpene hydrocarbons (1.7\%), sesquiterpene hydrocarbons $(0.2 \%)$, oxygenated sesquiterpenes $(0.5 \%)$ and no-terpenic compounds (0.1) were present in very small amounts (Table 1). The main components of this oil were linalool (59.0\%), a-terpineol (14.5\%) and geraniol (12.4\%), followed by appreciable amounts of nerol (3.7\%) and piperitone (3.6\%) (Table 1).

Table 1. Chemical Composition of Solenostemma oleifolium Essential Oil

\begin{tabular}{|c|c|c|c|c|c|}
\hline $\mathrm{N}^{\circ a}$ & Components & $\mathbf{R i a}^{\mathrm{b}}$ & $\operatorname{Ria}^{\mathrm{c}}$ & EO \% ${ }^{d}$ & Identification ${ }^{\mathrm{e}}$ \\
\hline 1 & Hexanal & 805 & 804 & 0.1 & $\mathrm{RI}, \mathrm{MS}$ \\
\hline 2 & $\alpha$-Pinene & 932 & 930 & 0.1 & $\mathrm{RI}, \mathrm{MS}$ \\
\hline 3 & $\beta$-Myrcene & 991 & 992 & 0.3 & $\mathrm{RI}, \mathrm{MS}$ \\
\hline 4 & Limonene & 1027 & 1027 & 0.4 & $\mathrm{RI}, \mathrm{MS}$ \\
\hline 5 & (Z)- $\beta$-ocimène & 1037 & 1040 & 0.2 & $\mathrm{RI}, \mathrm{MS}$ \\
\hline 6 & (E)- $\beta$-Ocimene & 1050 & 1050 & 0.4 & $\mathrm{RI}, \mathrm{MS}$ \\
\hline 7 & (E)-Linalool oxide & 1074 & 1073 & 0.2 & $\mathrm{RI}, \mathrm{MS}$ \\
\hline 8 & $\alpha$-Terpinolene & 1088 & 1087 & 0.3 & $\mathrm{RI}, \mathrm{MS}$ \\
\hline 9 & Linalool & 1113 & 1115 & 59.0 & RI, MS \\
\hline 10 & Camphor & 1145 & 1147 & 0.1 & $\mathrm{RI}, \mathrm{MS}$ \\
\hline 11 & Nerol oxide & 1153 & 1156 & 0.2 & $\mathrm{RI}, \mathrm{MS}$ \\
\hline 12 & Terpinen-4-ol & 1179 & 1180 & 0.2 & $\mathrm{RI}, \mathrm{MS}$ \\
\hline 13 & $\alpha$-Terpineol & 1200 & 1202 & 14.5 & $\mathrm{RI}, \mathrm{MS}$ \\
\hline 14 & Nerol & 1228 & 1230 & 3.7 & $\mathrm{RI}, \mathrm{MS}$ \\
\hline 15 & Piperitone & 1260 & 1259 & 3.6 & $\mathrm{RI}, \mathrm{MS}$ \\
\hline 16 & Geraniol & 1265 & 1268 & 12.4 & $\mathrm{RI}, \mathrm{MS}$ \\
\hline 17 & $\alpha$-Citral & 1277 & 1280 & 0.1 & $\mathrm{RI}, \mathrm{MS}$ \\
\hline 18 & Thymol & 1303 & 1301 & 1.3 & $\mathrm{RI}, \mathrm{MS}$ \\
\hline 19 & (E)- $\beta$-Damascenone & 1385 & 1383 & 0.2 & $\mathrm{RI}, \mathrm{MS}$ \\
\hline 20 & (E)- $\beta$-Caryophylene & 1418 & 1417 & 0.2 & $\mathrm{RI}, \mathrm{MS}$ \\
\hline 21 & (E)-Geranyl acetone & 1456 & 1454 & 0.1 & $\mathrm{RI}, \mathrm{MS}$ \\
\hline 22 & Caryophyllene oxide & 1581 & 1582 & 0.1 & $\mathrm{RI}, \mathrm{MS}$ \\
\hline 23 & $\beta$-Eudesmol & 1653 & 1653 & 0.1 & $\mathrm{RI}, \mathrm{MS}$ \\
\hline \multicolumn{4}{|c|}{$\%$ Identification } & \multicolumn{2}{|l|}{97.8} \\
\hline \multicolumn{4}{|c|}{$\begin{array}{l}\% \text { Monoterpene } \\
\text { hydrocarbons }\end{array}$} & \multicolumn{2}{|l|}{0.1} \\
\hline \multicolumn{4}{|c|}{$\begin{array}{l}\% \text { Oxygenated } \\
\text { monoterpenes }\end{array}$} & \multicolumn{2}{|l|}{95.3} \\
\hline \multicolumn{4}{|c|}{$\begin{array}{l}\% \text { Sesquiterpene } \\
\text { hydrocarbons }\end{array}$} & \multicolumn{2}{|l|}{0.2} \\
\hline \multicolumn{4}{|c|}{$\begin{array}{l}\% \text { Oxygenated } \\
\text { sesquiterpenes }\end{array}$} & \multicolumn{2}{|l|}{0.5} \\
\hline \multicolumn{4}{|c|}{$\%$ No-terpenic compounds } & \multicolumn{2}{|l|}{1.4} \\
\hline
\end{tabular}

a Order of elution is given on apolar column (DB-5).

${ }^{b}$ Retention indices of literature on the apolar column (IRla) reported from Konig et al.; 2001 and National Institute of Standards and Technology, 1999.

c Retention indices on the apolar DB-5 column (Rla).

${ }^{d}$ Percentage calculated by GC-FID on non-polar DB-5 capillary column.

Abbreviations: RI, retention indices; MS, Mass spectra in electronic impact mode.
Antioxidant Activity

The antioxidant activity was evaluated using the radical scavenging activity and reducing power methods, using ascorbic acid as positive control. Free radical scavenging capacity of the essential oil measured by DPPH assay is shown in Table 2. The essential oil was able to reduce the stable free radical DPPH to the yellow colored diphenylpicrylhydrazine with an $\mathrm{IC}_{50}$ value of $23.3 \mathrm{~g} / \mathrm{L}$, which was lower to positive control (ascorbic acid $\mathrm{IC}_{50}=0.047 \mathrm{~g} / \mathrm{L}$ ).

The reducing power was used to measure the antioxidant capability of essential oil. Reductive ability was determined by monitoring the $\mathrm{Fe}^{3+}$ to $\mathrm{Fe}^{2+}$ transformation in the presence of the essential oil. Figure 1 depicts the reducing power of S. oleifolium essential oil. According to the results shown in Figure 1, essential oil showed the presence of the reductive effects, with $\mathrm{EC}_{50}$ of $36.12 \mathrm{~g} / \mathrm{L}$ which was slightly lower to positive control $\left(\mathrm{EC}_{50}=45.03 \mathrm{~g} / \mathrm{L}\right)$.

\section{Discussion}

In this study, S. oleifolium essential oil composition and its antioxidant activity were evaluated. According to the literature survey of this research, there is only one report of the chemical composition of the essential oil of S. oleifolium. The chemical composition of this specie from Mascara (Algeria) showed that the essential oil was dominated by thujone $(43,7 \%)$, trans-sabinene hydrate (10.4\%), eugenol (8.4\%), 1.8-cineole (7.9\%), limonene (4.1\%) and a-pinene (3,57\%). ${ }^{11}$ The chemical composition of essential oil studied by Chouitah et $\mathrm{al}^{12}$ and this study showed significant differences in their chemical compositions. This difference may be explained by the differences in ecological conditions, altitude and climate. However, genetic differences are much higher than those caused by varying environmental conditions, which causes the occurrence of several chemical races or chemotypes within the same species. ${ }^{13}$ The results of this study on $S$. oleifolium revealed the existence of many components that are used in the pharmaceutical and cosmetic industries. For example, linalool is a monoterpene compound which exists in many plants. Linalool displays antimicrobial, antiinflammatory, analgesic, antihyperalgesic and antioxidant activities. ${ }^{14}$ Geraniol is widely used in cosmetics; it is used as tonic. Its action is essentially felt on the skin. It can also be used as a masking agent, that is to say it masks the odors of other components of the cosmetic. ${ }^{15}$ The antioxidant properties of $S$. oleifolium essential oil are probably related to their active components. Indeed, linalool, is a terpenoid alcohol, with a floral and fresh smell. It is found in a majority of essential oils such as lavender and mint. It has been proven that linalool reduces the levels of nuclear factor-erythroid. ${ }^{16}$ In

Table 2. DPPH radical-scavenging activity of Solenostemma oleifolium essential oil

\begin{tabular}{lllllcc}
\hline Sources & & & Antioxidant activity & \\
\hline \multirow{2}{*}{ Essential oil } & Concentration (g/L) & 0.03 & 0.6 & 2.0 & 4.0 & 6.0 \\
& DPPH Radical [\%] & $6.4 \pm 1.3$ & $27.3 \pm 1.3$ & $42.7 \pm 1.6$ & $60.1 \pm 2.3$ & $77.7 \pm 3.1$ \\
\multirow{2}{*}{ Ascorbic acid } & Concentration (g/L) & 0.04 & 0.05 & 0.06 & 0.08 & 0.2 \\
& DPPH Radical [\%] & $39.4 \pm 3.2$ & $51.0 \pm 4.3$ & $68.6 \pm 5.1$ & $97.9 \pm 6.7$ & $98.4 \pm 6.1$ \\
\hline
\end{tabular}




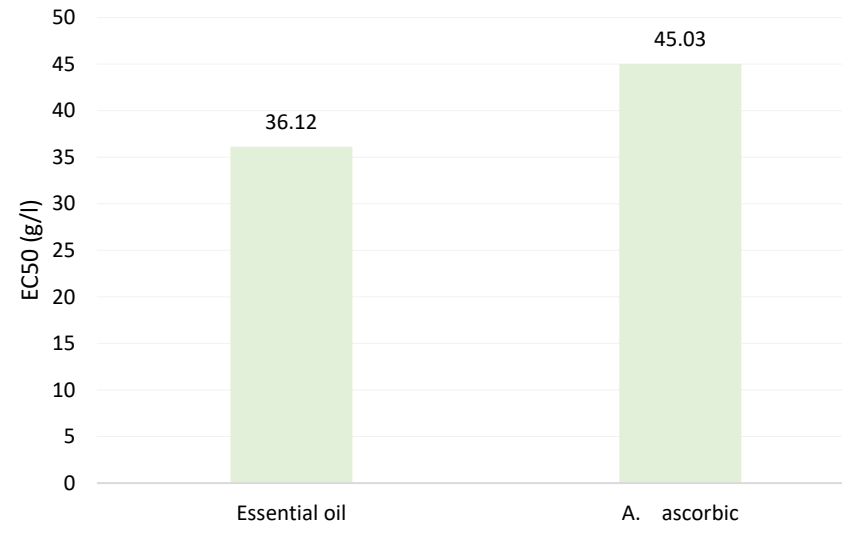

Figure 1. Reducing Power Assay Of Essential Oil and A. ascorbic.

addition, linalool was found to be effective as an antioxidant in guinea pig brains injected with $\mathrm{H}_{2} \mathrm{O}_{2} \cdot{ }^{14}$ As it was previously mentioned, $a$-terpineol proved to possess a potent antioxidant activity against free radicals causing injury. ${ }^{17}$ Moreover, a-terpineol exerted cytostatic activities against many human cancer cell lines such as leukemia, ovarian, breast adenocarcinoma and chronic myeloid leukemia. ${ }^{18}$ Bicas et $\mathrm{al}^{19}$ showed that $\alpha$-terpineol had an antioxidant potential similar to BHA (butylated hydroxyanisole) and possess a potential protective activity in foodstuffs. The antioxidant activity of geraniol has been reported by several authors. ${ }^{20,21}$ Geraniol proved to be a good scavenger of DPPH free radical with $\mathrm{IC}_{50}$ value of $663 \mathrm{nmol}$. Geraniol also exerted anti-tumor activity against various cancer cells both in vitro and in vivo tests. ${ }^{22,23}$ On the other hand, the antioxidant activity is probably due to the synergy between components of the oil. It has been proved that the combination of thymol and linalool or limonene and caryophyllene enhances antioxidant activity. ${ }^{24,25}$

\section{Conclusions}

In the current study, the chemical composition of the essential oil of S. oleifolium from Algeria has been investigated for the first time. The studied chemical composition was mainly composed of oxygenated monoterpenes such as linalool and geraniol, which constitute a range of interesting bioactive compounds. The results of antioxidant activity showed that the essential oil of $S$. oleifolium presented a good antioxidant effect with both tests. This activity may be partly due to major components or to the effect caused by the interaction of all constituents present in the oil. However, further research is necessary to study whether this essential oil can be used in the food or pharmaceutical industries or not.

\section{Authors' Contributions}

IC prepared the samples and analyzed the chemical composition; MAD wrote the manuscript; FD performed the antioxidant activities test; DM analyzed the results; and $\mathrm{HC}$ supervised the project.

\section{Conflict of Interest Disclosures}

The authors declare they have no conflicts of interest.

\section{Ethical Approval}

Not applicable.

\section{References}

1. Xu W, Zhang F, Luo Y, Ma L, Kou X, Huang K. Antioxidant activity of a water-soluble polysaccharide purified from Pteridium aquilinum. Carbohydr Res. 2009;344(2):217-222. doi:10.1016/j. carres.2008.10.021.

2. Lanigan RS, Yamarik TA. Final report on the safety assessment of BHT (1). Int J Toxicol. 2002;21 Suppl 2:19-94. doi:10.1080/10915810290096513.

3. Valko M, Leibfritz D, Moncol J, Cronin MT, Mazur M, Telser J. Free radicals and antioxidants in normal physiological functions and human disease. Int J Biochem Cell Biol. 2007;39(1):44-84. doi:10.1016/j.biocel.2006.07.001.

4. Magi G, Marini E, Facinelli B. Antimicrobial activity of essential oils and carvacrol, and synergy of carvacrol and erythromycin, against clinical, erythromycin-resistant Group A Streptococci. Front Microbiol. 2015;6:165. doi:10.3389/fmicb.2015.00165.

5. Lv F, Liang $\mathrm{H}$, Yuan Q, Li C. In vitro antimicrobial effects and mechanism of action of selected plant essential oil combinations against four food-related microorganisms. Food Res Int. 2011;44(9):3057-3064. doi:10.1016/j.foodres.2011.07.030.

6. Hammiche V, Maiza K. Traditional medicine in Central Sahara: pharmacopoeia of Tassili N'ajjer. J Ethnopharmacol. 2006;105(3):358-367. doi:10.1016/j.jep.2005.11.028.

7. Benchelah A-C, Bouziane H, Maka M. Fleurs du Sahara, arbres et arbustes, voyage au cœur de leurs usages avec les Touaregs du Tassili. Phytotherapie. 2004;2(6):191-197. doi:10.1007/s10298004-0052-z.

8. Vandendool H, Kratz PD. A generalization of the retention index system including linear temperature programmed gas-liquid partition chromatography. J Chromatogr. 1963;11:463-471. doi:10.1016/s0021-9673(01)80947-x.

9. Bozin B, Mimica-Dukic N, Simin N, Anackov G. Characterization of the volatile composition of essential oils of some lamiaceae spices and the antimicrobial and antioxidant activities of the entire oils. J Agric Food Chem. 2006;54(5):1822-1828. doi:10.1021/ jf051922u.

10. Aidi Wannes W, Mhamdi B, Sriti J, et al. Antioxidant activities of the essential oils and methanol extracts from myrtle (Myrtus communis var. italica L.) leaf, stem and flower. Food Chem Toxicol. 2010;48(5):1362-1370. doi:10.1016/j.fct.2010.03.002.

11. Chouitah O, Meddah B, Aoues A, Sonnet P. Chemical composition and antimicrobial activities of the essential oil from leaves of Solenostemma argel. Int J Biosci. 2016;9(6):360-365. doi:10.12692/ijb/9.6.360-365.

12. Zouari N. Essential Oils Chemotypes: A Less Known Side. Med Aromat Plants. 2013;2(2):e145. doi:10.4172/2167$0412.1000 \mathrm{e} 145$.

13. Celik S, Ozkaya A. Effects of intraperitoneally administered lipoic acid, vitamin E, and linalool on the level of total lipid and fatty acids in guinea pig brain with oxidative stress induced by H2O2. J Biochem Mol Biol. 2002;35(6):547-552. doi:10.5483/ BMBRep.2002.35.6.547.

14. Ansel JL. Les arbres à parfums. Paris: Librairie Eyrolles; 2001.

15. Wu Q, Yu L, Qiu J, et al. Linalool attenuates lung inflammation induced by Pasteurella multocida via activating Nrf-2 signaling pathway. Int Immunopharmacol. 2014;21(2):456-463. doi:10.1016/j.intimp.2014.05.030.

16. Sabino CKB, Ferreira-Filho ES, Mendes MB, et al. Cardiovascular effects induced by $\alpha$-terpineol in hypertensive rats. Flavour Fragr J. 2013;28(5):333-339. doi:10.1002/ffj.3159.

17. Khaleel C, Tabanca N, Buchbauer G. $\alpha$-Terpineol, a natural monoterpene: a review of its biological properties. Open Chem. 2018:16(1):349-361. doi:10.1515/chem-2018-0040.

18. Bicas JL, Neri-Numa IA, Ruiz AL, De Carvalho JE, Pastore GM. Evaluation of the antioxidant and antiproliferative potential of bioflavors. Food Chem Toxicol. 2011;49(7):1610-1615. doi:10.1016/j.fct.2011.04.012.

19. Prasad SN, Muralidhara. Protective effects of geraniol (a 
monoterpene) in a diabetic neuropathy rat model: attenuation of behavioral impairments and biochemical perturbations. J Neurosci Res. 2014;92(9):1205-1216. doi:10.1002/jnr.23393.

20. Tiwari M, Kakkar P. Plant derived antioxidants - Geraniol and camphene protect rat alveolar macrophages against t-BHP induced oxidative stress. Toxicol In Vitro. 2009;23(2):295-301. doi:10.1016/j.tiv.2008.12.014.

21. Yu SG, Hildebrandt LA, Elson CE. Geraniol, an inhibitor of mevalonate biosynthesis, suppresses the growth of hepatomas and melanomas transplanted to rats and mice. J Nutr. 1995;125(11):2763-2767. doi:10.1093/jn/125.11.2763.

22. Duncan RE, Lau D, El-Sohemy A, Archer MC. Geraniol and beta-ionone inhibit proliferation, cell cycle progression, and cyclin-dependent kinase 2 activity in MCF-7 breast cancer cells independent of effects on HMG-CoA reductase activity. Biochem Pharmacol. 2004;68(9):1739-1747. doi:10.1016/j. bcp.2004.06.022.

23. Neffati A, Bouhlel I, Ben Sghaier M, et al. Antigenotoxic and antioxidant activities of Pituranthos chloranthus essential oils. Environ Toxicol Pharmacol. 2009;27(2):187-194. doi:10.1016/j. etap.2008.10.010.

24. Asensio CM, Nepote V, Grosso NR. Chemical stability of extravirgin olive oil added with oregano essential oil. J Food Sci. 2011;76(7):S445-450. doi:10.1111/j.1750-3841.2011.02332.x. 